\title{
A Deficit in Familiarity-Driven Recognition in a Right-Sided Mediodorsal Thalamic Lesion Patient
}

\author{
Nicola M. J. Edelstyn and James A. Grange \\ Keele University
}

Simon J. Ellis

University Hospital of North Staffordshire, Stoke-on-Kent, United Kingdom, and Keele University

\author{
Andrew R. Mayes \\ University of Manchester
}

\begin{abstract}
Objective: According to a still-controversial view of recognition, projections between the perirhinal cortex and the medial subdivision of the mediodorsal thalamic nucleus (mMDT) support the mnemonic processes underlying familiarity, whereas a separate extended hippocampal system is critical for the recollection of episodic details during recognition. Method: In this study, we examined item recognition, familiarity, and recollection for faces and words in a patient (OG) with a right-sided lesion centered on the mMDT, which encroached on the central medial midline nucleus and may have resulted in partial disconnection of the mammillothalamic tract. On the basis of OG's neuropathology, the dual-process signal-detection (DPSD) high-threshold theory and the material-specific hypothesis of long-term memory together predicted a material-specific impairment in familiarity for novel facial memoranda, with a lesser decline in recollection of novel faces at short retention intervals. No abnormalities in either familiarityor recollection-driven recognition of verbal memoranda were expected. Results: Comparing the performance of OG and that of a group of 10 age-, sex-, and IQ-matched healthy controls, the remember-know procedure revealed the dissociations predicted by the material-specific and DPSD hypotheses: With recognition of previously novel faces, OG showed a deficit in familiarity-driven recognition that was significantly greater than the insignificant reduction in his recollection. All components of his word recognition were, however, preserved. Conclusion: A memory profile, marked by a dissociation between familiarity and recollection, fits naturally with the DPSD model and is incompatible with the idea that these kinds of memories reflect different degrees of trace strength.
\end{abstract}

Keywords: mediodorsal thalamus, material specificity, recognition, remember-know, recollection familiarity

There is still disagreement about the extent to which the underlying processes that drive familiarity and recollection of episodic information during recognition memory are nonoverlapping and, relatedly, the extent to which they depend on distinct neural mechanisms, particularly in the medial temporal lobes (MTLs) and their direct connections in the midline diencephalon (e.g., Aggle-

AQ: 1 ton \& Brown, 1999; Atkinson \& Juola, 1973; Cohen et al., 2008; Donaldson, 1996; Dunn, 2004; Jacoby \& Dallas, 1981; Mandler,

Nicola M. J. Edelstyn and James A. Grange, School of Psychology, Keele University; Simon J. Ellis, University Hospital of North Staffordshire Stoke-on-Kente United Kingdom, and Institute for Science and Technology in Medicine, Keele University; Andrew R. Mayes, School of Psychological Sciences, University of Manchester.

Financial support for this study from the Research Institute for Life Course Studies, Keele University, is acknowledged. We thank OG and the healthy volunteers for participating in this study and Charlotte Cooper for assisting with the development of the recognition memory tasks.

Correspondence concerning this article should be addressed to Nicola M. J. Edelstyn, School of Psychology, Universita Keele, Staffordshire ST5 5BG, United Kingdom. E-mail: n.edelstyn@keele.ac.uk
1980; Montaldi \& Mayes, 2010; Parks \& Yonelinas, 2007; Rotello, Macmillan, Reeder, \& Wong, 2005; Squire, Wixted, \& Clark, 2007; Wixted, 2007; Wixted \& Mickes, 2010; Wixted \& Squire, 2011; Yonelinas, Aly, Wang, \& Koen, 2010).

Recollection occurs when a studied stimulus cues the recall of one or more contextual details linked to the stimulus. This cued recall usually strongly confirms that the stimulus was previously encountered. Familiarity occurs when a studied stimulus feels as if it has been encountered previously without the occurrence of any cued recall. It also confirms stimulus recognition, but simply as a function of how strongly the stimulus feels familiar.

On the one hand, there are models, such as the dual-process signal-detection (DPSD) hypothesis (Yonelinas, 1994; for reviews, see Aggleton \& Brown, 1999; Yonelinas, 2002), that propose that the processes that respectively underlie recollection and familiarity are partially distinct and have different neural bases in the MTLs. The DPSD hypothesis also proposes that recollection varies continuously in strength from strong to weak but that below its strength threshold, nothing is recollected that supports discrimination between studied and nonstudied items (Yonelinas et al., 2010). This kind of memory involves several processes, mediated by a neural system that involves the hippocampus, fornix, mammillary bodies, mammillothalamic tract (MTT), and anterior nucleus of the 
EDELSTYN, GRANGE, ELLIS, AND MAYES

thalamus. In contrast, familiarity varies continuously in strength in a normally distributed manner and is well described by signaldetection theory. This kind of memory is mediated by a system that involves the perirhinal cortex, a projection from the perirhinal cortex, via the dorsal amygdala/external capsule and then via the inferior thalamic peduncle, to the medial subdivision of the mediodorsal thalamic nucleus (mMDT; Haskins, Yonelinas, Quamme, \& Ranganath, 2008; Montaldi, Spencer, Roberts, \& Mayes, 2006; Russchen, Amaral, \& Price, 1987; Saunders, Mishkin, \& Aggleton, 2005; Vann et al., 2009) and perhaps projections to the ventromedial frontal cortex (for review, see Aggleton, 2012; Eichenbaum, Yonelinas, \& Ranganath, 2007; Montaldi \& Mayes, 2010; Ranganath, 2010). Accounts like this predict a double dissociation between recollection and familiarity following selective lesions of the hippocampal-anterior thalamic or perirhinal cortexmMDT brain networks, respectively.

A recent thalamic extension of the Aggleton and Brown (1999) model (Aggleton, Dumont, \& Warburton, 2011) provided a possible mechanism by which recollection impairments can develop following pathology that falls outside of the core hippocampal system. This multieffect multinuclei (MEMN) model includes the DPSD proposal that the core hippocampal system is selectively critical for recollection and the perirhinal-mMDT circuit for familiarity but adds the suggestion that other medial thalamic nuclei-comprising the intralaminar (eenter median), and midline (central medial, paraventricular, parataenial, rhomboid, reuniens) thalamic nuclei-can influence recollection. The suggestion is that they do this either by modulating a subcortical-cortical arousal and attention system that includes the reticular activating system and the reticular thalamic nucleus (Portas et al., 1998; Van der Werf, Witter, \& Groenewegen, 2002; Van Der Werf, Jolles, Witter \& Uylings, 2003) or by disrupting learning and memory by disconnecting indirect projections between the intralaminar (eenter median) and midline (central medial, paraventricular, parataenial, rhomboid, reuniens) thalamic nuclei and the hippocampal formation (Amaral \& Cowan, 1980). The MEMN model also suggests that damage to the midline nuclei could impair familiarity because, like the mMDT, a subset of these midline nuclei (paraventricular, parataenial, rhomboid, reunion) are connected with the perirhinal and entorhinal cortices (see Aggleton et al., 2011; Pergola et al., 2012). Consequently, damage to the midline nuclei may also cause a familiarity deficit.

The mMDT and the intralaminar and midline thalamic nuclei reside in close proximity to each other, so lesions of the mMDT may extend to these nuclei and, consequently, have the potential to disrupt both kinds of memory. However, it is important to note that when this happens, any decline in recollection may be secondary to reticular thalamic nucleus damage that disrupts the subcorticalcortical arousal and attention system; disruption of connections between the midline and intralaminar thalamic nuclei, disrupting the mnemonic processes supported by the extended hippocampal system; or both of these.

On the other hand, there are models, such as the single-process unequal-variance signal-detection (UVSD) model (e.g., Donaldson, 1996; Dunn, 2004; Rotello et al., 2005; Squire et al., 2007; Wixted, 2007; Wixted \& Mickes, 2010; Wixted \& Squire, 2011), that propose that familiarity and recollection are not two kinds of memory mediated by separate perirhinal and hippocampal systems, respectively, but involve common underlying processes that are mediated by the same MTL structures and, presumably, their extramedial temporal lobe connections. The UVSD model implies that, although familiarity and recollection signals may sometimes occur in relative isolation, they are usually combined in a recognition memory strength signal such that the likelihood of a positive recognition decision is a function of perceived memory strength. As such, the combined signal varies on a continuum of recognition memory strength, with recollection typically making a strong contribution that leads to confident, fast, and accurate recognition judgments. Familiarity, in contrast, is often less confident and diagnostic, often yielding less accurate contributions to recognition, although when the familiarity signal is strong, it can support highly confident, diagnostic, and accurate contributions to recognition, just like recollection. According to this view, the extended hippocampal and perirhinal cortex systems support both strong and weak recognition memory in a functionally homogeneous way, regardless of whether this is driven primarily by recollection or by familiarity. Damage, therefore, to either system should disrupt both kinds of memory, although recollection-being typically stronger and, therefore, more functionally demanding than familiarity of their common support structures-is likely to be more seriously disrupted following small lesions (see Montaldi \& Mayes, 2010). By the same reasoning, small lesions in the perirhinal cortex system should impair the typically weak familiarity less than they impair the typically stronger recollection.

It remains disputed whether hypotheses like the DPSD view (and its MEMN extension) or the UVSD view best explain the effects of lesions within the MTLs, because different studies have found discrepant results, for reasons that are not currently understood (see Diana, Yonelinas, \& Ranganath, 2007; Eichenbaum et al., 2007; Montaldi \& Mayes, 2010; Ranganath, 2010; Wixted \& Squire, 2004). There has been very little exploration of whether recollection/familiarity dissociations are found following specific thalamic damage, and here the problem is exacerbated by several factors, which include the rarity of patients with ischemic lesions in diencephalic structures of interest. In vivo measurement of structural or functional disruption/integrity of the gray matter nuclei and white matter tracts in the densely packed thalamus is an order of magnitude harder than the equivalent (already difficult) task for the MTLs because of the much smaller size of the critical thalamic nuclei relative to MTL structures, such as the hippocampus, and the relatively low spatial resolution of most contemporary structural MRI protocols (for a recent review, see Carlesimo, Lombardi, \& Caltagirone, 2011; for details of recent strategies for better identification of thalamic nuclei, see Saranathan, Tourdias, Bayram, Ghanouni, \& Rutt, 2015; Serra et al., 2013; Tourdias, Saranathan, Levesque, Su, \& Rutt, 2014).

Functional MRI_(fMRI) indicates that recollection and familiarity rely on distinct neural substrates (e.g., Montaldi et al., 2006; Vilberg \& Rugg, 2007; Yonelinas, Otten, Shaw, \& Rugg, 2005; see also Diana et al., 2007), and Montaldi et al.'s event-related fMRI study in particular provided indirect support for mMDT involvement in familiarity memory. In that study, self-reported familiarity strength for scenes was associated with activation in a network of structures that included the perirhinal cortex and the left mediodorsal thalamic nucleus (MDT) as well as other structures, including the insula, left superior temporal cortex, left ventrolateral and anteromedial frontal cortex, posterior cingulate cortex, and left parietal neocortex. Hippocampal activity was not 
modulated by changes in familiarity strength even when this was matched to the strength of recollection, which activated the hippocampus more, contrary to the UVSD model. The activation within the region of the MDT, reported in Montaldi et al. and in a later study of object familiarity and recollection by Kafkas and Montaldi (2014), seems unlikely to have involved the lateral or parvicellular MDT, because lesion research implicates this part of the MDT in recall/recollection (Pergola \& Suchan, 2013).

To date, the evidence that disruption of the perirhinal-mMDT circuit impairs familiarity at all, let alone familiarity exclusively in clinical cases, is sparse (Bowles et al., 2007; Martin, Bowles, Mirsattari \& Köhler, 2011; see reviews by Carlesimo et al., 2011, 2015; Pergola \& Suchan, 2013). Although a number of studies have reported selective recollection deficits following damage to the hippocampus and its midline diencephalic projections (for a review, see Montaldi \& Mayes, 2010), there have been far fewer studies exploring whether perirhinal cortex lesions disrupt familiarity (and, if so, whether this effect is selective) and none, as far as we know, of whether lesions to its thalamic projections have similar effects. There have been some large group studies of aging participants suggesting a selective familiarity-disruptive effect of damage to perirhinal cortex and related medial temporal neocorical regions (e.g., Wolk et al., 2011; Yonelinas et al., 2007). One ase study of a patient, NB, who had suffered left anterior temporal cortex damage, which included large parts of the perirhinal and entorhinal cortex-damage, found-using several measures comprising the remember-know procedure, an examination of receiver operating characteristics, and a response deadline procedure - that she had a selective impairment of word familiarity during recognition testing (Bowles et al., 2007; Bowles, O'Neil, Mirsattari, Poppenk, \& Köhler, 2011; Martin et al., 2011). Both structural MRI and fMRI indicated that the hippocampus was working normally, which was consistent with NB's preserved verbal recollection (Bowles et al., 2007, 2011; Martin et al., 2011).

The aim of our study was to investigate familiarity- and recollection-driven recognition of verbal and facial memoranda in a patient, OG, with a right-sided medial MDT lesion that may have also resulted in a less extensive, partial disconnection of the MTT. Both UVSD and DPSD views of recognition, together with the material-specific hypothesis of long-term memory, predict that our patient's right-sided diencephalic lesion will be marked by an unfamiliar facial but not verbal recognition impairment over short retention intervals. However, the UVSD view predicts that recollection will be at least as impaired as familiarity and probably more so because it is typically stronger and more demanding of the structures that support it. In contrast, the DPSD view (and its MEMN extension) predicts that familiarity will be at least as impaired as recollection and probably more so provided that damage to the MTT is minor and that the structures that the MEMN model proposes to be recollection supportive have either only minor to no damage or turn out not to be recollection supportive.

These predictions were tested using two yes/no recognition memory tasks (RMTs) designed to separately assess verbal and facial recognition. Both tasks were extensively piloted prior to their use in this study to ensure that they were demanding but not so difficult that performance would be at floor. Estimates of recollection of episodic details and the assessment of familiarity during recognition were obtained using the remember-know procedure (Tulving, 1985). The remember-know procedure was cho- sen in preference to process estimation methods (e.g., the process dissociation procedure [Jacoby, 1991]; receiver operating characteristic curves [Yonelinas \& Parks, 2007]; structural equation modeling [Quamme, Yonelinas, Widaman, Kroll, \& Sauve, 2004]) which provide overall indications of performance. The rememberknow procedure was used properly by ensuring that participants were carefully instructed; checks were made to ensure that they were doing as instructed and understood correctly what recollection and familiarity were, so the procedure differentiated between recollection and familiarity on a trial-by-trial basis with sufficient accuracy to draw valid conclusions as, for example, by fMRI (for AQ: 8 a full discussion of these points, see Migo, Mayes, \& Montaldi, 2012).

The UVSD model cannot explain the kind of double dissociation predicted by the DPSD hypothesis (see Montaldi \& Mayes, 2010) unless its supporters can persuasively argue that it is in some way artifactual. They might attempt to do this by using the UVSD framework to argue that if familiarity was underreported and recollection overreported, a patient might artifactually appear to have impaired familiarity and intact recollection. This could occur, on the UVSD strength view, if the recognition strength (or confidence) threshold for recollection was lowered by patients, who became willing to report, as recollected, stimuli they were less confident they had recognized. These patients would then be correspondingly less willing to report as familiar these more confidently recognized stimuli, so their "weaker" familiarity responses should be less accurate and able to discriminate studied from unstudied stimuli, giving the artifactual appearance of a familiarity deficit. It is unclear, however, whether this lowering of patients' recognition confidence threshold for reporting recollection would lead to the illusion that their recollection was as able to discriminate studied and unstudied stimuli as that of controls. This is because the inclusion of recollection that is less confident in this sense might well lower the average ability to make this discrimination rather than raise it at all, let alone to normal levels. In other words, it may raise the hit rate, but it will also raise the false alarm rate so as to reduce studied-unstudied discrimination ability. The overreporting of recollection and underreporting of familiarity argument is, therefore, an uncertain means of showing that any apparently normal patient recollection, and disproportionately impaired familiarity, is an artifact. It is also based on what we think is the false view that recollection/familiarity decisions reflect levels of recognition confidence rather than judgments about whether one has recalled study-context details. Despite these two problems of the argument, we tested the possibility that our patient was overreporting recollection by seeing whether his recollection reporting bias was shifted in the direction of greater liberality. To do this, we used signal-detection theory as implied by the UVSD model and the assumption that the familiarity/recollection decision threshold is based on confidence/memory strength, as argued by, for example, Dunn (2004) and Wixted (2007). We also tested whether the patient's familiarity was unreported because of his familiarity bias shifting in the opposite and more conservative direction to his liberal recollection bias.

There is also uncertainty about whether stimuli that were very familiar even prior to a study episode, such as words or famous faces, can be recognized as having occurred in the study episode on the basis of item familiarity alone or if a form of item-study context associative familiarity as well as recollection is necessary 
for accurate performance (although the existence of item-study context associations is contentious; see Montaldi \& Mayes, 2010). However, faces that were novel prior to the study episode should be easily recognizable on the basis of item familiarity alone, because people only need to recognize whether they have seen studied faces anywhere before (see Smith et al., 2014). Face-study context associative familiarity is only likely to be important when people are asked to recognize in which of two study contexts previously novel faces appeared earlier. We, therefore, used remember-know procedure instructions that were focused on simple face familiarity and had only one study episode.

\section{Participants and RMTs}

\section{Participants}

The patient. The patient, OG, is a 74-year-old right-handed man with an estimated IQ in the high average range: 116 (National Adult Reading Test [NART; Nelson \& Willison, 1991]; see Table

1). OG formally worked as an electrical engineer before retiring in 2000. He now enjoys an active lifestyle, spending time playing bridge, cooking for himself and his wife, walking up to 25 miles per week, and caring for his grandchildren. OG had a 30-year history of visual migraines and hypertension prior to suffering an ischemic stroke in 2000. Apart from the resultant focal mMDT lesion, no other ischemic changes were evident on his magnetic resonance scan (performed in 2010 and reported in more detail in the next section).

OG has a material-specific selective impairment in visual item recognition and visual recall memory and sparing of verbal item recognition and verbal recall (Doors and People Test [Baddeley, Emslie, \& Nimmo-Smith, 1994]; Rey Complex Figure Test [My-

AQ: 9 ers \& Myers, 1995]; Logical Memory subtest [Wechsler, 1993]; see Edelstyn, Mayes, Denby, \& Ellis, 2012).

His short-term memory (STM) and working memory (Forward Digit Span and Forward Spatial subtests, Reverse Spatial, and

Table 1

Demographic and Neuropsychological Characteristics of Patient $O G$ and the Healthy Control Group

\begin{tabular}{|c|c|c|c|c|c|}
\hline \multirow[b]{2}{*}{ Participant } & \multirow[b]{2}{*}{ Age (years) } & \multirow[b]{2}{*}{ IQ } & \multicolumn{3}{|c|}{$\begin{array}{l}\text { Hospital Anxiety and } \\
\text { Depression Scale }\end{array}$} \\
\hline & & & Anxiety & Depression & Total \\
\hline HC 1 & 66 & 111 & 5 & 1 & 6 \\
\hline HC 2 & 72 & 119 & 5 & 0 & 5 \\
\hline $\mathrm{HC} 3$ & 72 & 122 & 0 & 0 & 0 \\
\hline HC 6 & 72 & 117 & 5 & 2 & 7 \\
\hline $\mathrm{HC} 8$ & 74 & 117 & 6 & 1 & 7 \\
\hline HC 10 & 69 & 124 & 3 & 2 & 5 \\
\hline HC 11 & 66 & 120 & 10 & 0 & 10 \\
\hline HC 13 & 66 & 119 & 4 & 4 & 8 \\
\hline HC 14 & 63 & 117 & 4 & 1 & 5 \\
\hline HC 15 & 63 & 114 & 4 & 1 & 5 \\
\hline$M$ & 68.30 & 118.00 & 4.60 & 1.20 & 5.80 \\
\hline $1 S D$ & 4.03 & 3.74 & 2.50 & 1.23 & 2.62 \\
\hline OG & 74 & 116 & 3 & 3 & 6 \\
\hline Mod. $t$ & 1.35 & -0.51 & & & 0.07 \\
\hline$p$ & .11 & .31 & & & .47 \\
\hline
\end{tabular}

Note. $\mathrm{HC}=$ healthy control; Mod. $=$ modified.
Digit Span; Wechsler, 1997) are also intact on all but the most taxing of tasks (Letter/Number Sequence; Wechsler, 1997). Attention is spared under conditions of low demand (Unimodal Vigilance, Unimodal Selective Attention, and Simple Flexibility subtests; Zimmermann \& Fimm, 1995) but impaired under high task demand (Bimodal Vigilance, Divided Attention, Complex Flexibility, and Covert Attention subtests; Zimmermann \& Fimm, 1995). Evidence of executive dysfunction is also present on some tests (the Hayling Test of response initiation and response inhibition [Burgess \& Shallice, 1997]; phonetic and semantic fluency) but not others (the Brixton Test of spatial anticipation [Burgess \& Shallice, 1997]; alternating fluency; see Edelstyn, Mayes, \& Ellis, 2014).

The healthy control group. A group of 10 healthy men was matched to OG for age, modified $t(\bullet \bullet)=1.35, p=.11$; premorbid $\mathbf{A Q}$ : $\mathbf{1 0}$ crystallized intelligence (NART), modified $t(\bullet \bullet)=-0.51, p=.31$; and anxiety and depression, modified $t(\bullet \bullet \bullet)=0.07, p=47$. The Hospital Anxiety and Depression Scales (Zigmond \& Snaith, 1983) provided control data for the RMTs. Participant demographic and neuropsychological characteristics are presented in Table 1.

A onymity and study approval. The patient's initials have AQ: 11 Changed to preserve anonymity. This study was approved by the North Staffordshire National Health Service research ethics committee and conducted in accordance with good clinical practice (European Medicines Agency, 2002).

\section{Structural Brain Imaging}

The structural magnetic resonance images were acquired using a 3Tesla Magnetron Trio whole-body imaging system (Siemens Healthcare, Erlangen, Germany). A series of 10 consecutive $\mathrm{T}_{2}$-weighted horizontal slices (slice thickness $=1 \mathrm{~mm}$ ) are shown in Figure 1. The following sequence parameters were used: repe- F1 tition time $=1,960 \mathrm{~ms}$, echo time $=4.43 \mathrm{~ms}$, inversion time $=$ $1,100 \mathrm{~ms}$, flip angle $=8^{\circ}$, and field of view $=256 \times 256 \mathrm{~mm}$. AQ: 12

The scans were visualized using aR

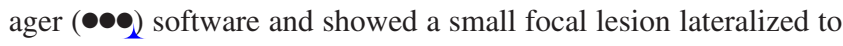
the right medial subdivision of the MDT. Apart from normal age-related changes and the focal medial thalamic lesion, no additional neuropathology was evident on the scans.

Previously published MRIs showed that OG's lesion also encroached on the internal medullary lamina, the central lateral intralaminar nucleus, the central medial and paraventricular midline nuclei, the parvicellular and paralamellar subdivisions of the MDT, and the MTT, thereby partially disconnecting the indirect hippocampal projections to the anterior thalamus that run via the mammillary bodies. The ventrolateral portion of the dorsal thalamus also appeared to be damaged. The anterior, ventral, and lateral thalamic nuclei were spared (see Edelstyn et al., 2012, 2014).

\section{Yes/No RMTs}

Stimuli. The verbal RMT was constructed from 98 4-6-letter words (mean word frequency $=229.2$ per million [range: 831,789], mean concreteness $=462.7$, and mean imageability $=$ 491.2) using the norms provided by Coltheart (1981) and Baayen, Piepenbrock, and van Rijn (1993). The pool comprised 49 highfrequency words (mean word frequency $=229.2$ per million 


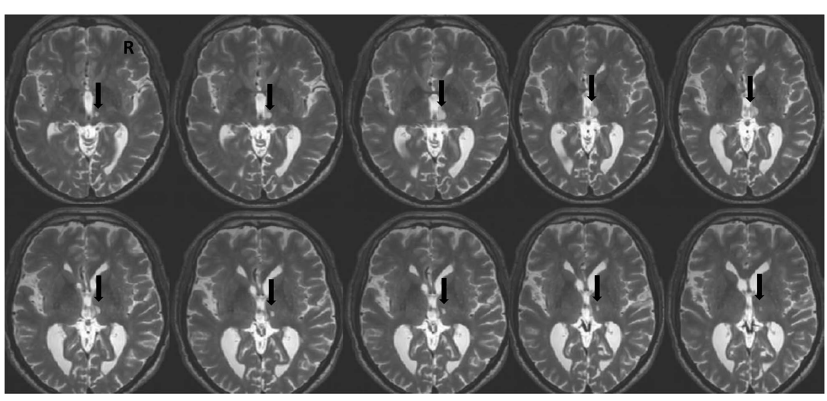

Figure 1. Ten consecutive horizontal magnetic resonance MR slices (thickness $=1 \mathrm{~mm}$ ) showing patient OG's right lateralized lesion centered on the magnocellular subdivision of his mediodorsal thalamic nucleus. $\mathrm{R}=$ right of midline.

[range: $83-1,789$ ], mean concreteness $=462.7$, and mean imageability $=491.2$ ) and 49 low-frequency words (mean word frequency $=1.9$ per million [range: $1-3$ ], mean concreteness $=$ 472.1 , and mean imageability $=482.7$ ). Twenty-four words from each pool were combined to form the target set and the lure set (i.e., $n s=48$, respectively). Both sets were matched for word frequency (targets: $M=115.4$ per million [range: $1-1,461]$, $S D=160.51$; lures: $M=115.65$ per million [range: $1-1,789$ ], $S D=160.87$ ), concreteness (targets: $M=467.9, S D=6.36$; lures: $M=466.9, S D=8.79$ ), and imageability (targets: $M=$ 487.2, $S D=6.08$; lures: $M=486.5, S D=5.66$ ). Forty-eight target verbal memoranda were presented at study, and these were randomly interleaved with 48 lures at test.

The visual RMT was constructed from 100 black-and-white photographic images of novel male and female faces of people between 18 and 60 years of age. Each image was presented face on, with the hair and ears cropped to exclude any additional contextual details that might have supported recognition.

The stimuli were presented on a 17-in. monitor at a viewing distance of $70 \mathrm{~cm}$. The visual angle subtended by the words was $0.82^{\circ}$ horizontal $\times 3.27^{\circ}$ (minimum) $-4.91^{\circ}$ (maximum) vertical (depending on the number of letters in the word), and for the facial images, the visual angle was $6.54^{\circ}$ horizontal $\times 8.58^{\circ}$ vertical. Fifty target facial memoranda were presented at study, and these were randomly interleaved with 50 lures at test.

Both RMTs were programmed in E-Prime Version 2 (Psychology Software Tools, Inc., Sharpsburg, PA; Schneider, Eschman, \& Zuccolotto, 2002).

Procedure. At study, participants saw the target memoranda for $3 \mathrm{~s}$ each (3-s interstimulus interval) and made a verbal judgment as to whether the item was pleasant or unpleasant. The verbal stimuli were presented once at study, whereas the facial stimuli were presented three times prior to the test phase (to avoid floor effects, on the basis of pilot work).

Immediately after completion of the study phase, recognition using the yes/no procedure was tested by presenting each of the targets randomly intermixed with a matched number of lures. Each item at test was presented individually, and yes/no recognition judgments were made within a 3 -s response window. Following each endorsement, irrespective of whether the item was a target or a lure, a second-stage remember-know judgment was made.

The same procedure was followed for both RMTs. They were completed in a sound-attenuated lab with normal lighting condi- tions, and the order of the verbal and facial RMTs was counterbalanced across participants.

Performance measures. Correct identification of a target item was defined as a hit, whereas false recognition of a lure was termed a false alarm. Following each endorsement, irrespective of whether it was a hit or false alarm, participants made a subjective judgment of their recognition experience in terms of either feelings of familiarity without any recollection (know response) or a specific recollection of the item having been previously presented (remember response). Although the second stage was not time constrained, participants were encouraged to respond as quickly as possible while remaining accurate. Participants were familiarized with the experimental set-up and the criteria for making remember and know decisions with a practice test prior to completing the main RMTs.

Remember-know instructions. Participants were instructed that a remember response could be given only if, when presented with a probe item, they recollected at least one of the following: (a) the item that appeared just before or after the currently tested probe item during the study session; (b) personal memories, mental images, or words that came to mind when the probe was presented during the study session; or (c) an emotional reaction that the currently tested probe triggered during the study session. These instructions aimed to ensure that recollection was only reported when a participant had recalled one or more things that he was thinking of when he was processing the probe during study.

Know responses were only recorded if participants recognized the probe as having been presented in the study session but did not recall any specific details associated with it from the study session. Although guess responses are sometimes also included in the remember-know procedure, they were not used here for two reasons. First, their use was unwarranted because familiarity memory discrimination scores were corrected using the familiarity false alarm rate. Therefore, if any familiarity response was really a guess rather than a weak familiarity response, this was fully corrected. Second, it was likely that the extra complexity would confuse participants. Such confusion is highly undesirable, because there is evidence that unless instructions are kept simple and are fully understood, participants can too frequently fail to follow them properly (for a full discussion of these points, see Migo et al., 2012).

Participants were asked to justify each remember and know judgment throughout the test phase to ensure that they maintained a full understanding of the criteria for making these types of decisions, in line with published recommendations on measuring recollection and familiarity using the remember-know procedure (Migo et al., 2012). The experimenter recorded recognition decisions on behalf of each participant. Endorsements of probes at test were entered as remember only if context was provided and as know in the absence of context.

Familiarity and recollection memory discrimination scores were calculated by first computing the familiarity and recollection hit rates and false alarm rates. To calculate the hit and false alarm rates for familiarity, it was assumed, following Yonelinas and Jacoby (1995), that familiarity responses are stochastically independent of each other. On the basis of fMRI data, introspective experience, and general plausibility arguments, there are strong reasons to suppose that this assumption is much nearer to reality than the assumption that familiarity and recollection have an 
exclusivity relationship or that every recollection response is always accompanied by a familiarity response (redundancy; for a full development of these arguments, see Migo et al., 2012). Applying the independence assumption to the corrected know scores, the reported measure of familiarity was calculated according to the following formula: know hit or false alarm rate/(1 remember hit or false alarm rate).

To eliminate extreme hit rates of 1 or 0 or false alarm rates of 0 , as the corresponding $z$ scores are infinite, all reported hit and false alarm rates have been corrected by adding 0.5 to each frequency and dividing by $N+1$, where $N$ is the number of old or new trials (Snodgrass \& Corwin, 1988). For consistency, this correction has been applied routinely, even in the absence of $0 \mathrm{~s}$ and $1 \mathrm{~s}$.

Estimates of item recognition and familiarity hit and false alarm rates were used to calculate a signal-detection index $\left(d^{\prime}\right)$, whereas a threshold measure of recollection (pr) was calculated by subtracting the recollection false alarm rate from the hit rate. The familiarity response bias was also measured using the signal- detection criterion (C). To examine the UVSD view that the presence of a familiarity deficit and sparing of recollection reflects a combination of familiarity underreporting (a conservative response bias) and recollection overreporting (a liberal response bias), the same response-bias measure (C) was also taken for recollection, following the arguments of Dunn (2004) and Wixted (2007).

\section{Results}

Recognition memory; know and remember hit and false alarm rates; and DPSD estimates of item recognition, recollection, and familiarity are reported for OG and the control group in Table 2 T2 and Figure 2. Standard $(z)$ scores, presented in Figure 3, and $\mathbf{F 2 , 3}$ modified $t$ tests have been used to indicate impairment (Singlims_ES.exe; Crawford \& Garthwaite, 2002).

At short retention intervals, OG showed a material-specific impairment in item recognition $(z=-2.83)$, modified $t(\bullet \bullet)=-2.69, p=.01$, and familiarity-driven recognition of

Table 2

Recognition Memory; Hit and False Alarm Rates; and Item Recognition, Recollection, and Familiarity for Patient OG and the Healthy Control Group

\begin{tabular}{|c|c|c|c|c|c|c|c|c|c|c|c|}
\hline \multirow[b]{2}{*}{ Participant } & \multicolumn{3}{|c|}{ Item recognition } & \multicolumn{2}{|c|}{ Remember } & \multicolumn{2}{|c|}{ Recollection } & \multicolumn{2}{|c|}{ Know } & \multicolumn{2}{|c|}{ Familiarity } \\
\hline & HR & FAR & $d^{\prime}$ & HR & FAR & $\mathrm{pr}$ & $\mathrm{C}$ & HR & FAR & $d^{\prime}$ & $\mathrm{C}$ \\
\hline \multicolumn{12}{|c|}{ Facial recognition memory } \\
\hline HC 1 & 0.81 & 0.02 & 2.13 & 0.26 & 0.01 & 0.25 & 1.80 & 0.56 & 0.11 & 1.94 & -0.09 \\
\hline HC 2 & 0.75 & 0.01 & 1.74 & 0.34 & 0.03 & 0.31 & 1.35 & 0.42 & 0.13 & 1.48 & 0.20 \\
\hline HC 3 & 0.93 & 0.02 & 1.89 & 0.64 & 0.19 & 0.45 & 0.09 & 0.30 & 0.17 & 1.81 & -0.57 \\
\hline HC 6 & 0.79 & 0.02 & 2.31 & 0.34 & 0.03 & 0.31 & 1.35 & 0.46 & 0.05 & 2.17 & 0.29 \\
\hline HC 8 & 0.72 & 0.01 & 1.54 & 0.21 & 0.11 & 0.10 & 1.44 & 0.52 & 0.07 & 1.82 & 0.32 \\
\hline HC 10 & 0.72 & 0.01 & 1.20 & 0.50 & 0.19 & 0.31 & 0.45 & 0.23 & 0.09 & 1.11 & 0.74 \\
\hline HC 11 & 0.87 & 0.02 & 2.19 & 0.70 & 0.03 & 0.67 & 0.43 & 0.19 & 0.13 & 1.41 & 0.27 \\
\hline HC 13 & 0.85 & 0.02 & 1.94 & 0.28 & 0.05 & 0.24 & 1.40 & 0.58 & 0.15 & 1.89 & -0.36 \\
\hline HC 14 & 0.85 & 0.02 & 1.62 & 0.15 & 0.07 & 0.08 & 1.79 & 0.72 & 0.23 & 1.69 & -0.64 \\
\hline HC 15 & 0.81 & 0.02 & 1.65 & 0.03 & 0.01 & 0.02 & 3.06 & 0.79 & 0.23 & 1.65 & -0.54 \\
\hline$M$ & 0.81 & 0.02 & 1.82 & 0.35 & 0.07 & 0.27 & 1.32 & 0.48 & 0.13 & 1.70 & -0.04 \\
\hline $1 S D$ & 0.07 & 0.00 & 0.34 & 0.21 & 0.07 & 0.19 & 0.85 & 0.20 & 0.06 & 0.30 & 0.47 \\
\hline OG & 0.68 & 0.34 & 0.86 & 0.44 & 0.17 & 0.27 & 0.63 & 0.25 & 0.19 & 0.61 & 0.53 \\
\hline$z$ score & & & -2.83 & & & 0.00 & -0.80 & & & -3.62 & 1.22 \\
\hline Mod. $t$ & & & -2.69 & & & 0.00 & -0.77 & & & -3.46 & 1.16 \\
\hline$p$ & & & 0.01 & & & 0.50 & 0.23 & & & 0.001 & 0.14 \\
\hline \multicolumn{12}{|c|}{ Word recognition memory } \\
\hline HC 1 & 0.93 & 0.03 & 3.38 & 0.89 & 0.50 & 0.88 & -0.07 & 0.05 & 0.03 & 1.77 & 1.06 \\
\hline HC 2 & 0.74 & 0.03 & 2.53 & 0.60 & 0.50 & 0.59 & 0.90 & 0.15 & 0.03 & 1.57 & 1.23 \\
\hline HC 3 & 0.91 & 0.13 & 2.44 & 0.64 & 2.50 & 0.59 & 0.45 & 0.28 & 0.05 & 2.35 & 0.06 \\
\hline HC 6 & 0.74 & 0.05 & 2.29 & 0.56 & 0.50 & 0.55 & 1.01 & 0.19 & 0.05 & 1.48 & 0.96 \\
\hline HC 8 & 0.64 & 0.30 & 0.90 & 0.23 & 2.50 & 0.18 & 1.54 & 0.42 & 0.26 & 0.73 & 0.19 \\
\hline HC 10 & 0.70 & 0.21 & 1.33 & 0.52 & 7.50 & 0.37 & 0.46 & 0.19 & 0.07 & 1.13 & 0.93 \\
\hline HC 11 & 0.97 & 0.03 & 3.74 & 0.95 & 0.50 & 0.94 & -0.48 & 0.03 & 0.03 & 2.12 & 0.68 \\
\hline HC 13 & 0.87 & 0.13 & 2.11 & 0.74 & 1.50 & 0.71 & 0.28 & 0.13 & 0.11 & 1.22 & 0.61 \\
\hline HC 14 & 0.85 & 0.09 & 2.35 & 0.64 & 0.50 & 0.63 & 0.79 & 0.21 & 0.01 & 2.57 & 0.90 \\
\hline HC 15 & 0.72 & 0.03 & 2.47 & 0.64 & 0.50 & 0.63 & 0.79 & 0.09 & 0.03 & 1.22 & 1.59 \\
\hline$M$ & 0.81 & 0.10 & 2.35 & 0.64 & 1.70 & 0.61 & 0.57 & 0.18 & 0.07 & 1.62 & 0.82 \\
\hline $1 S D$ & 0.11 & 0.09 & 0.83 & 0.20 & 2.20 & 0.22 & 0.57 & 0.11 & 0.07 & 0.58 & 0.46 \\
\hline OG & 0.87 & 0.03 & 2.99 & 0.52 & 0.50 & 0.51 & 1.11 & 0.36 & 0.03 & 2.53 & 0.28 \\
\hline$z$ score & & & 0.75 & & & -0.35 & 0.94 & & & 1.55 & -1.20 \\
\hline Mod. $t$ & & & 0.74 & & & -0.43 & 0.90 & & & 1.50 & -1.12 \\
\hline$p$ & & & 0.24 & & & 0.34 & 0.20 & & & 0.08 & 0.15 \\
\hline
\end{tabular}

AQ: 31 Note. Bolded values indicate $\cdots . .2 \mathrm{HR}=$ hit rate; FAR $=$ false alarm rate; $d^{\prime}=$ signal-detection index; $\mathrm{pr}=$ threshold measure of recollection; $\mathrm{C}=$ signal-detection criterion; $\mathrm{HC}=$ healthy control; Mod. = modified. 


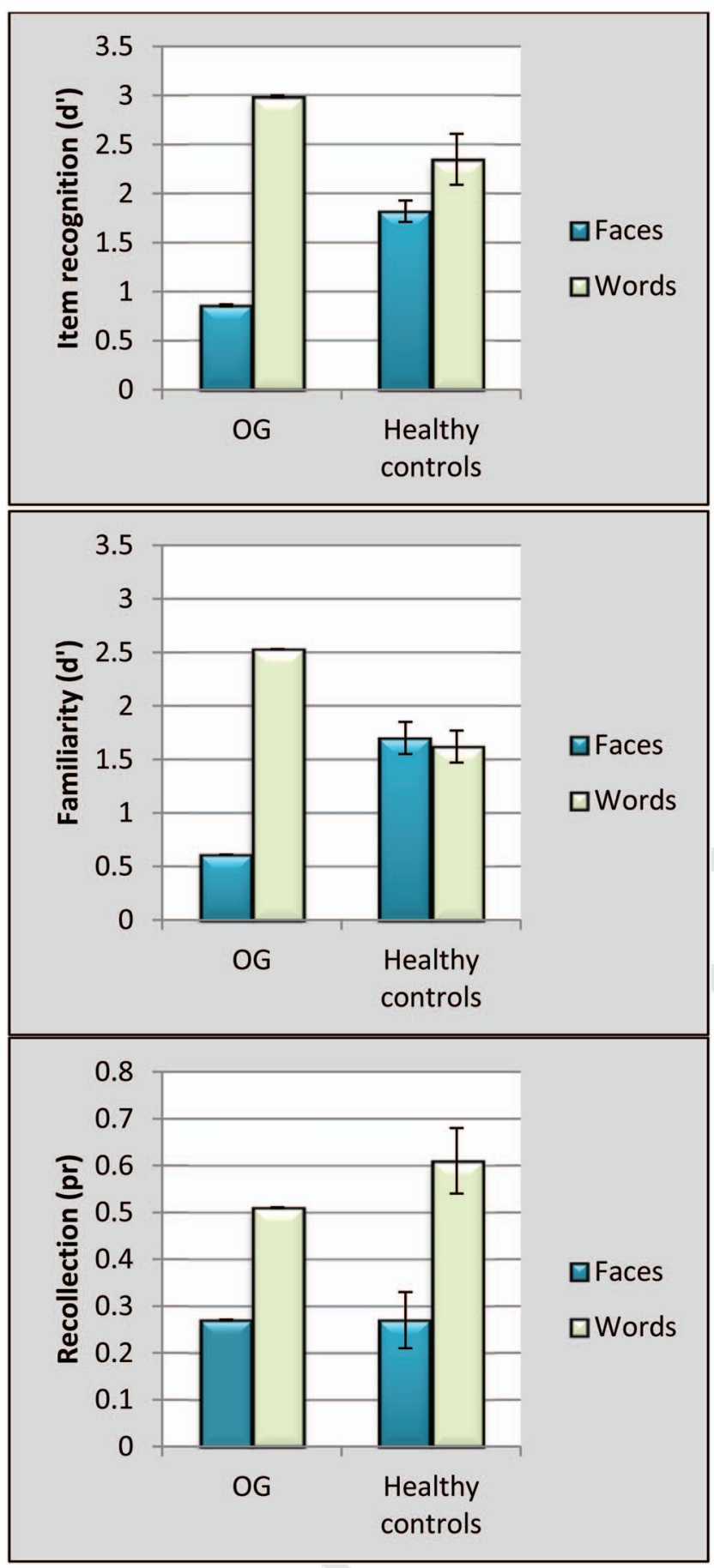

Figure 2. Item recognition $\left(d^{\prime}\right)$, familiarity $\left(d^{\prime}\right)$, and recollection (pr) rates for patient OG and the healthy control group.

unfamiliar facial memoranda $(z=-3.62)$, modified $t(\bullet \bullet)=-3.46, p=.001$. Recollection of novel facial memoranda, in contrast, was spared $(z=0.00)$. The familiarity response criterion of OG was not significantly more conservative than the criterion of the controls $(z=1.22)$, modified $t(\bullet \bullet)=1.16, p=$ .14 , and his recollection response criterion was not significantly more liberal than that of the controls $(z=-0.80)$, modified $t(\bullet \bullet)=-0.77, p=.23$.

Item memory, familiarity, and recollection of verbal memoranda at short retention intervals were also preserved (all $p \mathrm{~s}>.05$ ). There were no significant differences in response criteria between OG and the controls for either familiarity $(z=-1.20)$, modified $t(\bullet \bullet)=-1.12, p=.15$, or recollection $(z=0.94)$, modified $t(\bullet \bullet)=0.90, p=.20$.

In the next set of analyses, dissociations, suggested previously, were formally investigated (Revised Standardized Difference Test [Dissocs_ES.exe], one-tailed; Crawford \& Garthwaite, 2005; Crawford, Garthwaite, \& Porter, 2010). OG showed betweenmodality (novel facial vs. verbal) dissociations for item recognition (i.e., facial recognition was impaired, but verbal recognition was spared), modified $t(\bullet \bullet)=2.87, p=.02$, and familiarity (i.e., facial familiarity was impaired, but verbal familiarity was spared), modified $t(\bullet \bullet \bullet)=3.28, p<.01$, but not for recollection, modified $t(\bullet \bullet)=0.30, p=.77$. A within-modality (familiarity vs. recollection rates) dissociation was present for novel facial memoranda (i.e., OG's familiarity-driven recognition of faces was impaired, but his recollection rate was spared), modified $t(\bullet \bullet)=2.34, p=$ .04 , but absent for words, modified $t(\bullet \bullet)=1.43, p=.19$.

\section{Discussion}

The aim of this study was to further explore the functional relationship between the mMDT and the dual-process view of recognition in a patient with a right-sided lesion involving the mMDT and the central medial midline nucleus and that may have resulted in partial disconnection of the MTT. The key behavioral findings from this case report can be summarized as follows: First, OG showed a dissociation between (deficient) familiarity-driven recognition and (spared) recollection of facial memoranda, although his recollection and familiarity response biases did not differ from those of the controls. Second, OG showed no abnormalities in verbal item recognition, familiarity, and recollection. These results are discussed in relation to OG's previously documented neuropsychological profile to explore fully the implications of our findings in the context of the literature. The dissociation in OG's memory for novel faces (impaired) and words (preserved) at short retention intervals is consistent with an earlier study of this same patient in which a material-specific decline in visual memory on the Doors and People Test (Baddeley et al., 1994) and free recall on the Rey Complex Figure Test (Myers \& Myers, 1995) and preserved recognition memory and free recall of verbal memoranda (Logical Memory [Wechsler, 1995]; Doors and People Test [Baddeley et al., 1994]) was reported (Edelstyn et al., 2012). At that time, impairments were, therefore, reported not only in forced-choice recognition but also in free recall of visual memoranda, which may seem inconsistent with our current findings. It was suggested that decline in visual recognition was caused by disruption of the mMDT pathways on which processes supporting familiarity-driven recognition rely, whereas the impairment in immediate and delayed visual recall was linked to OG's rightsided lesion encroaching on the MTT and, thereby, partially disconnecting the indirect hippocampal projections to the anterior thalamic nucleus that run via the mammillary bodies. The probable reason why OG's previously reported visual recall of shapes was more impaired than his novel face recollection, which is reported 


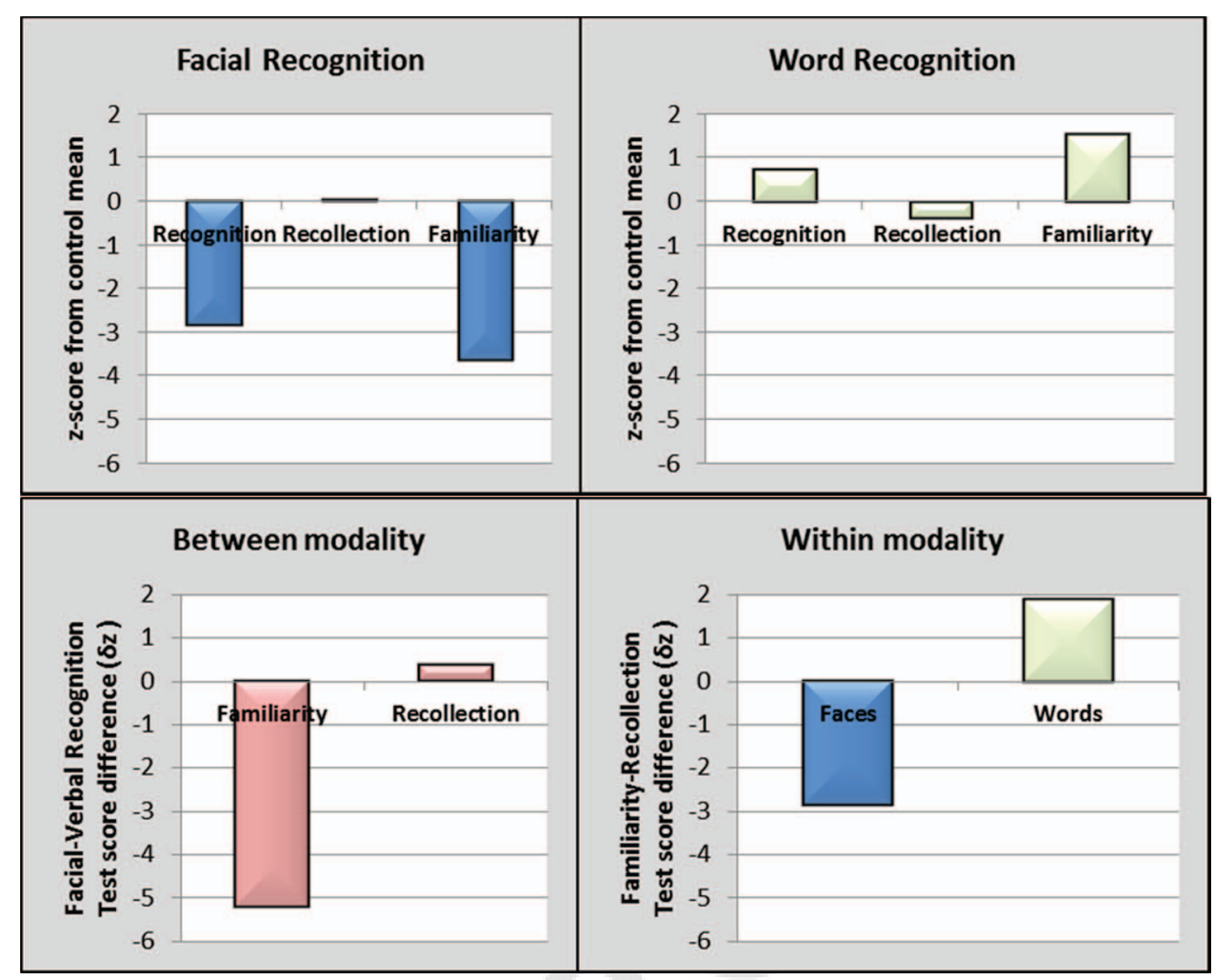

Figure 3. Estimates of patient OG's item recognition $\left(d^{\prime}\right)$, familiarity $\left(d^{\prime}\right)$, and recollection (pr) as standard scores $(z$ scores) for faces and words and as test score difference scores $(\delta z s)$ for between- and within-modality rates of familiarity and recollection.

here, are considered later. Our current findings also have implications for the unresolved debate regarding the importance of the mMDT and the extended hippocampal circuit for familiarity/recognition and recollection/recall.

According to the UVSD view, the hippocampus (and, presumably, the extended hippocampal system) supports both familiarity/ recognition and recollection/recall (Wixted, 2007; Wixted \& Squire, 2004, 2011). The dual-process view, conversely, states that only recollection is dependent on the hippocampus and associated structures-which include the fornix, the anterior thalamic nucleus, the MTT, and the mammillary bodies — whereas familiarity, and the recognition responses that depend on it, rely on a separate network of structures that critically involves the perirhinal cortex

AQ: 15 and the mMDT (Aggleton \& Brown, 1999, 2006; see also Yonelinas, 2002; Yonelinas et al., 2010).

We now consider whether there are currently any hypotheses other than a variant of the DPSD view that predict disproportionate deficits in familiarity memory relative to recollection after thalamic damage, as was found in OG. We focus, in particular, on the UVSD model. The UVSD view must imply that recollection and familiarity depend on overlapping structures not only in the MTL but also in the thalamus. It also proposes that remember responses typically generate more confident, diagnostic, and, therefore, accurate recognition memories than do know responses. Such "stronger" memory responses are proposed to activate the hippocampus more on average than are usually "weaker" responses, regardless of whether they depend on recollection signals, the less commonly strong familiarity signals, or both. The model also predicts that strong recognition responses should be more disrupted by incomplete lesions of this structure and its thalamic connections. Both the greater neuronal activity and the greater lesion sensitivity occur because these strong recognition responses are supposed to demand more of the resources of their mediating structures. By extension, using the UVSD functional homogeneity claim, incomplete lesions of not only the perirhinal cortex but also its diencephalic connections, such as the mMDT, should also impair recollection as well as familiarity, with recollection being at least as impaired as familiarity and possibly more impaired if sufficient residual resources remain functional. This kind of hypothesis, therefore, predicts that even if diencephalic lesions are truly selective and damage only parts of the extended hippocampal system, such as the anterior thalamic nucleus or the MTT-or only parts of the extended perirhinal cortex system, such as the mMDT - either recollection and familiarity will be equally impaired (if damage is extensive) or recollection will be more impaired (if damage is more incomplete). Effects of both kinds have been reported, although there is controversy about whether the lesions are truly selective in the way required by the UVSD model. For example, patients $\mathrm{RH}, \mathrm{JC}$, and VC were equally impaired at recollection and familiarity following lesions that involved the hippocampus but that spared the thalamus (Bird, Shallice, \& Cipolotti, 2007; Cipolotti, Bird, Good, Macmanus, Rudge, \& Shallice, 2006). Other thalamic lesion patients have shown greater recollection deficits, although these might be more consistent with 
the DPSD or UVSD views, depending on the extent and locus of the lesion. For example, if, as claimed by the authors (Carlesimo et al., 2007; Serra et al., 2013), patient GP had a truly selective bilateral mammillothalamic lesion with relative sparing of the intralaminar thalamic nucleus and MDT, his focal recollection deficit would be consistent with the DPSD view but not the UVSD view.

But neither of these patterns of breakdown were evident for OG. Instead, he showed a selective impairment in familiarity, with his novel face-triggered recollection, that was not even significantly impaired, showing significantly higher levels of sparing. The UVSD model can only explain our results with OG by assuming that he overreported recollection and consequentially underreported familiarity so as to produce the pattern observed. Otherwise, only variants of the DPSD predict this pattern of memory breakdown following a right-sided mMDT lesion, consistent with the structure playing a primary role in mediating familiarity-driven recognition memory. The counter to this conclusion is based on using the UVSD model to argue that OG may have been reporting recollection at a lower threshold of recognition memory strength than were the controls - that is, he used a more liberal strength criterion for recollection. The argument goes that this may have had the effect of improving recollection discrimination of studied versus unstudied faces so as possibly to normalize it. However, this would only have happened provided he did not show a marked increase in recollection false positives, which is likely, because if OG was willing to report less confident recognition as recollection, this would almost certainly have increased his false alarm rate. OG's possible bias might also have decreased his familiarity discrimination score, because he should have reported fewer strong familiarity responses. The UVSD view assumes that whether recollection or familiarity is reported depends solely on recognition memory strength. This assumption is wrong according to the DPSD model, because it also critically depends on whether a person feels he or she is or is not recalling study-context details that are not present. However, even ignoring these serious concerns about the validity of the UVSD argument, our findings showed that OG's criteria for both familiarity and recollection, calculated assuming signal-detection theory, did not differ from those of the controls. The UVSD argument does not, therefore, explain the findings obtained.

The conclusion that familiarity was impaired selectively by mMDT damage is strengthened, because OG's lesion may have partially disconnected his MTT and may also have included his central medial midline nucleus, a thalamic structure considered by the MEMN extension of the DPSD model. If the thalamic connectivity of the hippocampal system was partially disrupted by lesions of the central medial midline nucleus and/or the MTT, then the DPSD/MEMN view would predict a disruption of recollection such that any evidence of impaired recollection and free recall of visual information might be attributable this. Similarly, if OG's right-sided medial thalamic damage disrupted projections with other subcortical structures considered to modulate arousal and attention (Aggleton et al., 2011), then the DPSD/MEMN view again would predict that recollection would have been likely to have been more disrupted than familiarity insofar as it is more arousal and attention demanding.

Both of these arguments also provide an explanation of why OG's previously reported visual recall was more impaired than his novel facial recollection, for the following reasons. First, free recall demands more effort at encoding and test than does recollection (which is a more heavily cued form of recall), so if OG's medial thalamic damage extends into the midline and intralaminar thalamic nuclei, the disruption of arousal/attention would affect recall more than recollection. Second, if damage disrupts hippocampal projections-by encroaching on the MTT and/or the direct inputs between the central medial nucleus and the hippocampus - free recall may be more impaired, because it is more demanding of the extended hippocampal system's resources and so is more responsive to small amounts of damage. Recollection, conversely, is less demanding, as it is in essence a form of cued recall, with the probe cuing the retrieval of associations. Consider the Rey Complex Figure Test, which OG had particular difficulty recalling, as reported previously (Edelstyn et al., 2012). This figure comprises many separate elements, and although they may be unitized and recalled as a single entity at the local level, it is not possible to do this at the global level. Thus, this recall task is considerably more demanding than, for example, a novel facial recollection task, in which the intraitem associations between the eyes, nose, mouth, and so on are more readily bound together using the spatial template of the face (e.g., Diana, Yonelinas, \& Ranganath, 2008; Mayes et al., 2004). (This point is considered later in this section.) Accordingly, the inherent weakness within OG's episodic memory system, caused by the partial disconnection of the MTT or the direct inputs between the central medial nucleus and the hippocampus, only become evident when the system is challenged using the particular stimuli and tasks found most difficult.

If one or both of these kinds of additional thalamic damage is present in OG, even if the damage is slight, it is even more striking how well preserved his novel face-triggered recollection was. Further, the presence of such additional damage explains why OG's free recall was impaired on the Rey Complex Figure Test, as previously reported, even if damage to the right-sided mMDT did not disrupt recollection and free recall of visual stimuli at all, as the strong form of the DPSD view proposes (Edelstyn et al., 2012). Our study cannot, of course, resolve whether OG's face familiarity deficit was entirely attributable to mMDT damage or if additional damage to the midline nuclei also contributed to the familiarity impairment to an unknown degree, as suggested by the MEMN extension of the DPSD model.

OG's impairment in familiarity-driven recognition of novel faces fits well with Smith et al.'s (2014) recent study of patients with bilateral lesions of the hippocampus or more extensive ones of the MTL that included the perirhinal cortex. Both groups showed, even at a short retention interval, deficits in recognition memory of famous faces, inverted faces, buildings, and words, whereas only the MTL group was deficient in recognition memory of novel faces at this short retention interval. These findings imply that recognition of novel facial memoranda, unlike the other categories, is independent of the hippocampus but reliant on other MTL structures such as the perirhinal cortex. By implication, therefore, disruption of the perirhinal cortex within the MTL memory structures - or of the structures to which the perirhinal cortex projects, particularly the mMDT_-should be marked by a pronounced deficit in recognition memory of unfamiliar faces, which is precisely what we found with OG. 
Smith et al. (2014) suggested that novel faces-unlike famous faces, inverted faces, buildings, and words - can easily be processed holistically (as a single item rather than a conjunction of parts), so good recognition memory can be largely based on how novel or familiar individual faces feel at test rather than having to be based on identification of whether there is an association between an item and its study context. Whereas Smith et al. did not attempt to measure familiarity directly, we did, indicating that novel face recognition was indeed largely mediated by face familiarity. Smith et al.'s view is similar in some respects to the convergence, recollection, and familiarity theory (CRAFT; Montaldi \& Mayes, 2010), which also proposes that the perirhinal cortex binds object features rapidly together to form new unitized object memory representations that support item familiarity memory. Unlike Smith et al., CRAFT proposes that perirhinal cortex supports unitization of not only novel face inputs but also of other object/item inputs, but perhaps to a lesser degree than with novel AQ: 2 ces (for evidence, see Holdstock et al., 2002; Mayes, Holdstock, Isaac, Hunkin, \& Roberts, 2002). However, although CRAFT proposes that the perirhinal cortex forms direct (but not usually unitized) object-object associative memory representations, it also holds that all associations with different kinds of components that are processed in distinct medial temporal neocortical regions, such as item-context associations, converge mainly in the hippocampus, which creates pattern-separated representations that support only recollection. This is contrary to Smith et al., who seem to hold that item-context associations are formed in the hippocampus that are able to support both associative familiarity and recollection (which is, by definition, an associative form of memory). At present, there is no convincing evidence that there are associative familiarity memory-supporting, object-context associations, let alone that they are hippocampally created representations, supported by the hippocampus and not the perirhinal cortex (see Montaldi \& Mayes, 2010).

Given that relatively selective familiarity deficits have only rarely been reported, OG's familiarity deficiency for previously novel faces is a first step toward providing the opposite dissociation to reports of a severe and disproportionate impairment in recall/recollection and lesser impairment in recognition with preserved familiarity following lesions of the extended hippocampal circuit. This more common kind of dissociation has been reported quite often. For example, Mayes et al. (2002) described a patient, YR, who had bilateral hippocampal lesions and who showed a severe impairment in recall (mean $z=-3.6$ ), whereas recognition performance (across a total of 43 recognition tests) revealed much higher levels of preservation (mean $z=-0.5$ ), and Holdstock et al. (2002) found evidence that this patient's familiarity memory was fully preserved.

Similar disproportionate impairments in recall/recollection have been reported in other patients with lesions of the hippocampus (e.g., Aggleton et al., 2005; Bastin et al., 2004; patient PR, reported by Holdstock et al., 2008), the MTT (patient GP, reported by Carlesimo et al., 2007; Serra et al., 2013; see also review by Carlesimo et al., 2015), the anterior thalamus (patient QX, reported by Edelstyn, Ellis, Jenkinson, \& Sawyer, 2002; Edelstyn, Hunter, \& Ellis, 2006), and the fornix and the mammillary bodies (Tsivilis et al., 2008; Vann et al., 2009).

Taken together, OG's data, showing a dissociation between familiarity and recollection for faces add to the growing evidence base supporting the DPSD view that the neural structures supporting familiarity and recollection are dissociable. OG is not the first patient to show this pattern; it was first shown by patient NB, who demonstrated impaired familiarity and spared recollection following resection of the perirhinal cortex that spared the hippocampus (Bowles et al., 2007; Martin et al., 2011). OG is, nevertheless, as far as we are aware, the first to demonstrate a similar selective pattern of familiarity impairment following an mMDT lesion. The DPSD-consistent familiarity role of the MDT is also supported by recent complementary fMRI data showing that MDT blood oxygenation level-dependent activity is selectively up-regulated as object picture familiarity memory confidence and accuracy increases and that, when familiarity and recollection recognition accuracy are matched, this structure shows significantly greater activation with familiarity (Kafkas \& Montaldi, 2014).

\section{References}

Aggleton, J. P. (2012). Multiple anatomical systems embedded within the primate medial temporal lobe: Implications for hippocampal function. Neuroscience and Biobehavioral Reviews, 36, 1579-1596. http://dx.doi .org/10.1016/j.neubiorev.2011.09.005

Aggleton, J. P., \& Brown, M. W. (1999). Episodic memory, amnesia, and the hippocampal-anterior thalamic axis. Behavioral and Brain Sciences, 22, 425-444. http://dx.doi.org/10.1017/S0140525X99002034

Aggleton, J. P., Dumont, J. R., \& Warburton, E. C. (2011). Unraveling the contributions of the diencephalon to recognition memory: A review. Learning \& Memory, 18, 384-400. http://dx.doi.org/10.1101/lm .1884611

Aggleton, J. P., Vann, S. D., Denby, C., Dix, S., Mayes, A. R., Roberts, N., \& Yonelinas, A. P. (2005). Sparing of the familiarity component of recognition memory in a patient with hippocampal pathology. Neuropsychologia, 43, 1810-1823. http://dx.doi.org/10.1016/j.neuropsychologia.2005.01.019

Amaral, D. G., \& Cowan, W. M. (1980). Subcortical afferents to the hippocampal formation in the monkey. Journal of Comparative Neurology, 189, 573-591. http://dx.doi.org/10.1002/cne.901890402

Atkinson, R. C., \& Juola, J. F. (1973). Factors influencing the speed and accuracy of word recognition. In S. Kornblum (Ed.), Attention and performance IV (pp. 583-612). New York: Academic Press.

Baayen, R. H., Piepenbrock, R., \& van Rijn, H. (1993). The CELEX lexical database [CD-ROM]. Philadelphia: University of Pennsylvania, Linguistic Data Consortium.

Baddeley, A., Emslie, H., \& Nimmo-Smith, I. (1994). The Doors and People Test. Bury St. Edmunds, England: Thames Valley Test Company.

Barbas, H., Henien, T. H., \& Dermen, C. R. (1991). Diverse thalamie AQ: 19 projections to the prefrontal cortex in the rhesus monkey. Journal of Comparative Neurology, 313, 65-94. http://dx.doi.org/10.1002/ene 903130106

Bastin, C., Linden, M., Charnallet, A., Denby, C., Montaldi, D., Roberts, N., \& Andrew, M. (2004). Dissociation between recall and recognition memory performance in an amnesic patient with hippocampal damage following carbon monoxide poisoning. Neurocase, 10, 330-344. http:// dx.doi.org/10.1080/13554790490507650

Bowles, B., Crupi, C., Mirsattari, S. M., Pigott, S. E., Parrent, A. G., Pruessner, J. C., . . . Köhler, S. (2007). Impaired familiarity with preserved recollection after anterior temporal-lobe resection that spares the hippocampus. Proceedings of the National Academy of Sciences of the United States of America, 104, 16382-16387. http://dx.doi.org/ 10.1073/pnas.0705273104

Bowles, B., Crupi, C., Pigett, S., Parrent, A., Wiebe, S., Janzen, L., \& Köhler, S. (2010). Double dissociation of selective recollection and AQ:20 
familiarity impairments following two different surgical treatments for temporal lobe epilepsy. Neuropsychologia, 48, 2640-2647. http:I/dx.dei .erg/10.1016/j.neurepsychelegia.2010.05.010

Bowles, B., O’Neil, E. B., Mirsattari, S. M., Poppenk, J., \& Köhler, S. (2011). Preserved hippocampal novelty responses following anterior temporal-lobe resection that impairs familiarity but spares recollection. Hippocampus, 21, 847-854.

Burgess, P. W., \& Shallice, T. (1997). The Hayling and Brixton Tests. Bury St. Edmunds, England: Thames Valley Test Company.

Carlesimo, G. A., Lombardi, M. G., \& Caltagirone, C. (2011). Vascular thalamic amnesia: A reappraisal. Neuropsychologia, 49, 777-789. http:// dx.doi.org/10.1016/j.neuropsychologia.2011.01.026

Carlesimo, G. A., Lombardi, M. G., \& Caltagirone, C. (2015). Recollection and familiarity in the human thalamus. Neuroscience and Biobehavioral Reviews, 54, 18-28.

Carlesimo, G. A., Serra, L., Fadda, L., Cherubini, A., Bozzali, M., \& Caltagirone, C. (2007). Bilateral damage to the mammillo-thalamic tract impairs recollection but not familiarity in the recognition process: A single case investigation. Neuropsychologia, 45, 2467-2479. http://dx .doi.org/10.1016/j.neuropsychologia.2007.03.025

Coltheart, M. (1981). The MRC psycholinguistic database. Quarterly Journal of Experimental Psychology A: Human Experimental Psychology, 33, 497-505. http://dx.doi.org/10.1080/14640748108400805

Crawford, J. R., \& Garthwaite, P. H. (2002). Investigation of the single case in neuropsychology: Confidence limits on the abnormality of test scores and test score differences. Neuropsychologia, 40, 1196-1208. http://dx.doi.org/10.1016/S0028-3932(01)00224-X

Crawford, J. R., \& Garthwaite, P. H. (2005). Testing for suspected impairments and dissociations in single-case studies in neuropsychology: Evaluation of alternatives using Monte Carlo simulations and revised tests for dissociations. Neuropsychology, 19, 318-331. http://dx.doi.org/ 10.1037/0894-4105.19.3.318

Crawford, J. R., Garthwaite, P. H., \& Porter, S. (2010). Point and interval estimates of effect sizes for the case-controls design in neuropsychology: Rationale, methods, implementations, and proposed reporting standards. Cognitive Neuropsychology, 27, 245-260. http://dx.doi.org/10.1080/ 02643294.2010.513967

Diana, R. A., Yonelinas, A. P., \& Ranganath, C. (2007). Imaging recollection and familiarity in the medial temporal lobe: A three-component model. Trends in Cognitive Sciences, 11, 379-386. http://dx.doi.org/ 10.1016/j.tics.2007.08.001

Diana, R. A., Yonelinas, A. P., \& Ranganath, C. (2008). The effects of unitization on familiarity-based source memory: Testing a behavioral prediction derived from neuroimaging data. Journal of Experimental Psychology: Learning, Memory, and Cognition, 34, 730-740. http://dx .doi.org/10.1037/0278-7393.34.4.730

Donaldson, W. (1996). The role of decision processes in remembering and knowing. Memory \& Cognition, 24, 523-533. http://dx.doi.org/10.3758/ BF03200940

Dunn, J. C. (2004). Remember-know: A matter of confidence. Psychological Review, 111, 524-542. http://dx.doi.org/10.1037/0033-295X .111 .2 .524

Edelstyn, N. M. J., Ellis, S. J., Jenkinson, P., \& Sawyer, A. (2002). Contribution of the left dorsomedial thalamus to recognition memory: A neuropsychological case study. Neurocase, 8, 442-452. http://dx.doi .org/10.1076/neur.8.5.442.16180

Edelstyn, N. M. J., Hunter, B., \& Ellis, S. J. (2006). Bilateral dorsolateral thalamic lesions disrupts conscious recollection. Neuropsychologia, 44, 931-938. http://dx.doi.org/10.1016/j.neuropsychologia.2005.08.012

Edelstyn, N. M. J., Mayes, A. R., Denby, C., \& Ellis, S. J. (2012). Impairment in material-specific long-term memory following unilateral mediodorsal thalamic damage and presumed partial disconnection of the mammillo-thalamic tract. Journal of Neuropsychology, 6, 119-140. http://dx.doi.org/10.1111/j.1748-6653.2011.02019.x
Edelstyn, N. M. J., Mayes, A. R., \& Ellis, S. J. (2014). Damage to the dorsomedial thalamic nucleus, central lateral intralaminar thalamic nucleus, and midline thalamic nuclei on the right-side impair executive function and attention under conditions of high demand but not low demand. Neurocase, 20, 121-132. http://dx.doi.org/10.1080/13554794 2012.713497

Eichenbaum, H., Yonelinas, A. P., \& Ranganath, C. (2007). The medial temporal lobe and recognition memory. Annual Review of Neuroscience, 30, 123-152. http://dx.doi.org/10.1146/annurev.neuro.30.051606 .094328

European Medicines Agency. (2002, July). Guideline for good clinical practice. (ICH Topic E, 6 [R1]). London: Author.

Haskins, A. L., Yonelinas, A. P., Quamme, J. R., \& Ranganath, C. (2008). Perirhinal cortex supports encoding and familiarity-based recognition of novel associations. Neuron, 59, 554-560. http://dx.doi.org/10.1016/j .neuron.2008.07.035

Holdstock, J. S., Parslow, D. M., Morris, R. G., Fleminger, S., Abrahams, S., Denby, C., ... Mayes, A. R. M. (2008). Two case studies illustrating how relatively selective hippocampal lesions in humans can have quite different effects on memory. Hippocampus, 18, 679-691. http://dx.doi .org/10.1002/hipo.20427

Jacoby, L. L., \& Dallas, M. (1981). On the relationship between autobiographical memory and perceptual learning. Journal of Experimental Psychology: General, 110, 306-340. http://dx.doi.org/10.1037/00963445.110.3.306

Kafkas, A., \& Montaldi, D. (2014). Two separate, but interacting, neural systems for familiarity and novelty detection: A dual-route mechanism. Hippocampus, 24, 516-527. http://dx.doi.org/10.1002/hipo.22241

Kelley, W. M., Miezin, F. M., McDermott, K. B., Buckner, R. L., Raichle, M. E., Cohen, N. J., . . Petersen, S. E. (1998). Hemispherie specialization in human dorsal frental cortex and medial temporal lobe for verbal and nonverbal memory encoding. Neuron, 20, $927-936$. http://dx dei.0rg/10.1016/S0896-6273(00)80474-2

Mandler, G. (1980). Recognizing: The judgment of previous occurrence. Psychological Review, 87, 252-271. http://dx.doi.org/10.1037/0033295X.87.3.252

Martin, C. B., Bowles, B., Mirsattari, S. M., \& Köhler, S. (2011). Selective familiarity deficits after left anterior temporal-lobe removal with hippocampal sparing are material specific. Neuropsychologia, 49, 18701878. http://dx.doi.org/10.1016/j.neuropsychologia.2011.03.012

Mayes, A. R., Holdstock, J. S., Isaac, C. L., Hunkin, N. M., \& Roberts, N. (2002). Relative sparing of item recognition memory in a patient with adult-onset damage limited to the hippocampus. Hippocampus, 12, 325340. http://dx.doi.org/10.1002/hipo.1111

Mayes, A. R., Holdstock, J. S., Isaac, C. L., Montaldi, D., Grigor, J., Gummer, A., . . Norman, K. A. (2004). Associative recognition in a patient with selective hippocampal lesions and relatively normal item recognition. Hippocampus, 14, 763-784. http://dx.doi.org/10.1002/hipo .10211

Mayes, A., Mentaldi, D., \& Mige, E. (2007). Asseciative memery and the AQ: 22 medial temporal lobes. Frends in Cognitive Sciences, 11, 126-135. http://dx.dei.org/10.1016/j.ties.2006.12.003

Migo, E. M., Mayes, A. R., \& Montaldi, D. (2012). Measuring recollection and familiarity: Improving the remember/know procedure. Consciousness and Cognition, 21, 1435-1455. http://dx.doi.org/10.1016/j.concog 2012.04.014

Mitchell, A. S., \& Chakraborty, S. (2013). What does the mediodorsat AQ: 23 thatamus do? Frontiers in Systems Neuroseience, 7, 37. http:/ldx.doi .0rg/10.3389/fnsys.2013.00037

Montaldi, D., \& Mayes, A. R. (2010). The role of recollection and familiarity in the functional differentiation of the medial temporal lobes. Hippocampus, 20, 1291-1314. http://dx.doi.org/10.1002/hipo.20853 
Montaldi, D., Spencer, T. J., Roberts, N., \& Mayes, A. R. (2006). The neural system that mediates familiarity memory. Hippocampus, 16, 504-520. http://dx.doi.org/10.1002/hipo.20178

Myers, J. E., \& Myers, K. R. (1995). Rey Complex Figure Test. Odessa, FL: Psychological Assessment Resources.

Nelson, H. E., \& Willison, J. (1991). National Adult Reading Test. Windsor, England: NFER-Nelson.

Parks, C. M., \& Yonelinas, A. P. (2007). Moving beyond pure signaldetection models: Comment on Wixted (2007). Psychological Review, 114, 188-201. http://dx.doi.org/10.1037/0033-295X.114.1.188

Pergola, G., Güntürkün, O., Koch, B., Schwarz, M., Daum, I., \& Suchan, B. (2012). Recall deficits in stroke patients with thalamic lesions covary with damage to the parvocellular mediodorsal nucleus of the thalamus. Neuropsychologia, 50, 2477-2491. http://dx.doi.org/10.1016/j .neuropsychologia.2012.06.019

Pergola, G., \& Suchan, B. (2013). Associative learning beyond the medial temporal lobe: Many actors on the memory stage. Frontiers in Behavioral Neuroscience, 7, 162. http://dx.doi.org/10.3389/fnbeh.2013.00162

Portas, C. M., Rees, G., Howseman, A. M., Josephs, O., Turner, R., \& Frith, C. D. (1998). A specific role for the thalamus in mediating the interaction of attention and arousal in humans. Journal of Neuroscience, $18,8979-8989$.

Ranganath, C. (2010). A unified framework for the functional organization of the medial temporal lobes and the phenomenology of episodic memory. Hippocampus, 20, 1263-1290.

Rotello, C. M., Macmillan, N. A., Reeder, J. A., \& Wong, M. (2005). The remember response: Subject to bias, graded, and not a process-pure indicator of recollection. Psychonomic Bulletin \& Review, 12, 865-873. http://dx.doi.org/10.3758/BF03196778

Russchen, F. T., Amaral, D. G., \& Price, J. L. (1987). The afferent input to the magnocellular division of the mediodorsal thalamic nucleus in the monkey, Macaca fascicularis. Journal of Comparative Neurology, 256, 175-210. http://dx.doi.org/10.1002/cne. 902560202

AQ: 24 Saling, M. M. (2009). Verbal memory in mesial temperal lobe epilepsy: Beyond material specificity. Brain, 132, 570 582. http:/ldx.doi.org/ 10.1093/brain/awp012

Saranathan, M., Tourdias, T., Bayram, E., Ghanouni, P., \& Rutt, B. K. (2015). Optimization of white-matter-nulled magnetization prepared rapid gradient echo (MP-RAGE) imaging. Magnetic Resonance in Medicine, 73, 1786-1794. http://dx.doi.org/10.1002/mrm.25298

Saunders, R. C., Mishkin, M., \& Aggleton, J. P. (2005). Projections from the entorhinal cortex, perirhinal cortex, presubiculum, and parasubiculum to the medial thalamus in macaque monkeys: Identifying different pathways using disconnection techniques. Experimental Brain Research, 167, 1-16. http://dx.doi.org/10.1007/s00221-005-2361-3

Schneider, W., Eschman, A., \& Zuccolotto, A. (2002). E-Prime user's guide. Pittsburgh, PA: Psychology Software Tools.

Serra, L., Cercignani, M., Carlesimo, G. A., Fadda, L., Tini, N., Giulietti, G., . . Bozzali, M. (2013). Connectivity-based parcellation of the thalamus explains specific cognitive and behavioural symptoms in patients with bilateral thalamic infarct. PLOS ONE, 8, e64578 . http://dx .doi.org/10.1371/journal.pone.0064578

Smith, C. N., Jeneson, A., Frascino, J. C., Kirwan, C. B., Hopkins, R. O., \& Squire, L. R. (2014). When recognition memory is independent of hippocampal function. Proceedings of the National Academy of Sciences of the United States of America, 111, 9935-9940. http://dx.doi.org/ 10.1073/pnas. 1409878111

Snodgrass, J. G., \& Corwin, J. (1988). Pragmatics of measuring recognition memory. Applications to dementia and amnesia. Journal of Experimental Psychology: General, 117, 34-50.

Squire, L. R., Wixted, J. T., \& Clark, R. E. (2007). Recognition memory and the medial temporal lobe: A new perspective. Nature Reviews Neuroscience, 8, 872-883. http://dx.doi.org/10.1038/nrn2154
Tourdias, T., Saranathan, M., Levesque, I. R., Su, J., \& Rutt, B. K. (2014). Visualization of intra-thalamic nuclei with optimized white-matternulled MPRAGE at 7T. NeuroImage, 84, 534-545. http://dx.doi.org/ 10.1016/j.neuroimage.2013.08.069

Tsivilis, D., Vann, S. D., Denby, C., Roberts, N., Mayes, A. R., Montaldi, D., \& Aggleton, J. P. (2008). A disproportionate role for the fornix and mammillary bodies in recall versus recognition memory. Nature Neuroscience, 11, 834-842. http://dx.doi.org/10.1038/nn.2149

Tulving, E. (1985). Memory and consciousness. Canadian Psychology/ Psychologie canadienne, 26, 1-12. http://dx.doi.org/10.1037/h0080017

Van der Werf, Y. D., Jolles, J., Witter, M. P., \& Uylings, H. B. M. (2003). Contributions of thalamic nuclei to declarative memory functioning. Cortex, 39, 1047-1062. http://dx.doi.org/10.1016/S0010-9452(08)70877-3

Van der Werf, Y. D., Weerts, J. G. E., Jolles, J., Witter, M. P., Lindebeom, J., \& Scheltens, P. (1999). Neuropsychological-correlates of a right AQ: 25 unilateral lacunar thalamic infaretion. Journal of Neurology, Neuresur gery \& Psychiatry, 66, 36 42. http:/ldx.doi.org/10.1136/jnnp.66.1.36

Van der Werf, Y. D., Witter, M. P., \& Groenewegen, H. J. (2002). The AQ: 26 intralaminar and midline nuclei of the thalamus. Anatomical and funetional evidence for participation in processes of arousal and awareness. Brain Research Reviews, 39, 107 140. http://dx.doi.org/10.1016/S01650173(02)00181-9

Vann, S. D., Tsivilis, D., Denby, C. E., Quamme, J. R., Yonelinas, A. P., Aggleton, J. P., . . . Mayes, A. R. (2009). Impaired recollection but spared familiarity in patients with extended hippocampal system damage revealed by 3 convergent methods. Proceedings of the National Academy of Sciences of the United States of America, 106, 5442-5447. http://dx.doi.org/10.1073/pnas.0812097106

Vilberg, K. L., \& Rugg, M. D. (2007). Dissociation of the neural correlates of recognition memory according to familiarity, recollection, and amount of recollected information. Neuropsychologia, 45, 2216-2225. http://dx.doi.org/10.1016/j.neuropsychologia.2007.02.027

Wagner, D. D., Sziklas, V., Garver, K. E., \& Jones-Gotman, M. (2009). AQ: 27 Material-specific lateralization of working memery in the medial temperal lobe. Neuropsychologia, 17, 112 122. http://dx.doi.org/10.1016/j neuropsychologia.2008.08.010

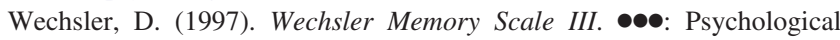
Corporation, Hareeurt Brace.

Wixted, J. T. (2007). Dual-process theory and signal-detection theory of recognition memory. Psychological Review, 114, 152-176. http://dx.doi .org/10.1037/0033-295X.114.1.152

Wixted, J. T., \& Mickes, L. (2010). A continuous dual-process model of remember/know judgments. Psychological Review, 117, 1025-1054. http://dx.doi.org/10.1037/a0020874

Wixted, J. T., \& Squire, L. R. (2004). Recall and recognition are equally impaired in patients with selective hippocampal damage. Cognitive, Affective, \& Behavioral Neuroscience, 4, 58-66. http://dx.doi.org/ 10.3758/CABN.4.1.58

Wixted, J. T., \& Squire, L. R. (2011). The medial temporal lobe and the attributes of memory. Trends in Cognitive Sciences, 15, 210-217. http:// dx.doi.org/10.1016/j.tics.2011.03.005

Wixted, J. T., \& Stretch, V. (2004). In-defense of the signal-detection AQ: 29 interpretation of remember/know judgments. Psychenemic Bulletin \& Review, 11,616-641. http://dx.doi.org/10.3758/BF03196616

Yonelinas, A. P. (1994). Receiver-operating characteristics in recognition memory: Evidence for a dual-process model. Journal of Experimental Psychology: Learning, Memory, and Cognition, 20, 1341-1354. http:// dx.doi.org/10.1037/0278-7393.20.6.1341

Yonelinas, A. P. (2002). The nature of recollection and familiarity: A review of 30 years of research. Journal of Memory and Language, 46, 441-517. http://dx.doi.org/10.1006/jmla.2002.2864

Yonelinas, A. P., Aly, M., Wang, W. C., \& Koen, J. D. (2010). Recollection and familiarity: Examining controversial assumptions and new 
directions. Hippocampus, 20, 1178-1194. http://dx.doi.org/10.1002/ hipo. 20864

Yonelinas, A. P., \& Jacoby, L. L. (1995). The relation between remembering and knowing as bases for recognition: Effects of size congruency. Journal of Memory and Language, 34, 622-643. http://dx.doi.org/ 10.1006/jmla.1995.1028

Yonelinas, A. P., Otten, L. J., Shaw, K. N., \& Rugg, M. D. (2005). Separating the brain regions involved in recollection and familiarity in recognition memory. Journal of Neuroscience, 25, 3002-3008. http://dx .doi.org/10.1523/JNEUROSCI.5295-04.2005
Zigmond, A. S., \& Snaith, R. P. (1983). The Hospital Anxiety and Depression Scale. Acta Psychiatrica Scandinavica, 67, 361-370. http://dx .doi.org/10.1111/j.1600-0447.1983.tb09716.x

Zimmermann, P., \& Fimm, B. (1995). Test for Attentional Performance (Version 1.02). Herzogenrath, Germany: Psytest.

Received December 1, 2014

Revision received May 28, 2015

Accepted May 31, 2015 